\title{
AC 2008-1203: BUILDING INFORMATION MODELING: THE IMPLICATIONS OF GOVERNMENT AND INDUSTRY INITIATIVES FOR AEC EDUCATION
}

\section{Stan Guidera, Bowling Green State University}

STAN GUIDERA is an Associate Professor in Architectural/Environmental Design Studies in the College of Technology at Bowling Green State University. He teaches design studios, advanced $\mathrm{CAD}$ courses and computer rendering and animation. He is a registered architect and has used computer-aided design extensively in professional practice.

\section{Anthony Mutai, Bowling Green State University}

ANTHONY MUTAI is a doctoral student in the College of Technology at Bowling Green State University specializing in Construction Management. He teaches construction management and estimating courses using BIM applications and is involved in research related to the implementation of BIM in construction processes. 


\title{
Building Information Modeling: Implications of Government and Industry BIM Initiatives for AEC Education
}

\begin{abstract}
This paper provides an overview of Building Information Modeling (BIM) and the key issues that have lead to the development of government and industry initiatives related to BIM. The implications of BIM for AEC curriculums are discussed and strategies for integrating content related to BIM in AEC coursework are proposed.
\end{abstract}

\section{Introduction}

Parametric object-based design tools have become standard in architectural CAD applications and the ability to utilize parametric control of geometry and dimensional relationships has become an expectation ${ }^{1}$. While the design flexibility and productivity afforded by parametric modeling positively impacts the role of computing in architectural design, the adoption of parametric computer modeling does not in itself dramatically alter the design process. However, this is not the case with the current generation of OOP-based architectural CAD applications which utilize Building Information Modeling (BIM). BIM applications integrate 3D-2D operations, which expands the conceptualization of computer modeling from an assembly of 3D geometry to that of a repository of project information and introduce a fully model-centric design process. The concept underlying BIM is using digital technologies to integrate all project data in order "to build a building virtually prior to building it physically, in order to work out problems, and simulate and analyze potential impacts" 2 .

Definitions of BIM vary, but common to most is an emphasis on the integration of project data. The American Institute of Architects (AIA) defined BIM as "a model-based technology linked with a database of project information" 3 . More specifically, BIM has been defined as a combination of graphical project data such as 2D and 3D drawings and non-graphical information including specifications and cost data ${ }^{4}$. Gallaher, O'Connor, Detbar, and Gilday proposed a definition that is somewhat broader in that it considered the project in terms of post construction. They defined BIM as utilizing "cutting edge digital technology to establish a computable representation of all the physical and functional characteristics of a facility and its related project/life-cycle information, and is intended to be a repository of information for the facility owner/operator to use and maintain throughout the life-cycle of a facility" 4 . The National Institute of Building Sciences published the following definition:

"Building information models, or BIMs (are) digital, easily managed and shared representations of physical and functional data that define buildings throughout their life cycles - are increasingly seen throughout the public and private real estate and construction sectors as a way to control cost and performance problems associated with inaccurate and incomplete communications" 5 . 
There is a necessary distinction that must be made between CAD and BIM. CAD, or computer aided design or drafting, is generally conceived of as an automated version of manual drafting. As in manual drafting, the use of lines and shapes produced representations of architectural elements such as walls and doors that were "generally incapable of corresponding to architectural elements in an appropriate manner" 6 . CAD "was simply a computerized drafting tool that did not significantly change the way architects practiced-it just computerized existing practice" 7 . While it is possible for CAD application to imbed information in CAD geometry and to link external data to graphical representations, these procedures are not central to productivity in the operation of the software. Similarly, most CAD applications provide a wide range of modeling tools. However, the emphasis of these applications is representation of data using geometric entities. Khamlani pointed out that while "traditional 2D CAD and generic 3D modeling programs internally represent data using geometric entities such as points, lines, rectangles, planes, etc ., and that while these applications can accurately describe geometry in any domain, they cannot capture domain-specific information about entities" 8 . 3D models alone do not qualify as BIM models since a 3D geometric representation is only part of the BIM concept $^{9}$.

BIM applications are distinguished from CAD by their use of object oriented programming as their underlying computation technology. Object oriented programming is computational ontology; a data model that represents a domain and is used to reason about the objects in that domain and the relations between them. Programmers define a data structure, and then define the operations that can be applied to that data structure. Therefore, the data structure is defined as an object that includes both data and functions with specified relationships between the object and other objects. Benefits include reduction of complexity, the ability to re-use or combine objects, and easy modification and extension of individual components without requiring recoding ${ }^{10}$. Consequently, architectural objects relate "intelligently" ${ }^{11}$ and function more intuitively: floors "know" they are to be horizontal and the components of a window "know" that they are part of a wall ${ }^{12}$. However, while object oriented programming provides the core technology utilized in BIM applications, models generated with OOP-based programs are not inherently BIM. Rather, it is the emphasis on information that is critical to BIM. In BIM, the object database is capable of "storing qualitative and quantitative information about the project" 5. Inherent in the object-oriented database underlying BIM applications is the ability to integrate design development and project management:

While a door represented in 2D-CAD is just a collection of lines, in BIM it is an intelligent object containing information on its size, cost, manufacturer, and more". This means that all information in the BIM is interconnected, and, when a change is made to an object in a database, all other affected objects and areas are immediately updated. For example, if a wall is deleted, doors and windows within the walls are also deleted, and all data on project scope, cost and schedule are instantly adjusted ${ }^{4}$.

Implicit in the interconnectedness of Building Information Modeling is an emphasis on collaboration. According to Elvin, "because BIM creates a comprehensive and dynamic model of the project, it requires intense collaboration and coordination" ${ }^{4}$. This position is supported by AGC president Harry Mashburn, who described BIM as "a mechanism for collaborative project delivery": 
It is making collaboration the top priority in execution of a project to ensure that everyone on the team-from the architect to the general contractor and the specialty contractor to the supplier-is working from a real-time, living model of the project. It allows us as contractors to use technological innovation to realize owners' demands for optimized results-time and cost savings-that is driving change in our industry ${ }^{13}$.

In addition to the potential productivity benefits, a key driver of the adoption of BIM are initiatives in both the design and construction industry. The Association of General Contractors (AGC) has launched the AGC BIM initiative, supported by a publication for members entitled "Contractors guide to BIM" ${ }^{13}$. The American Institute of Architects Technology in Architectural Practice (TAP) division has developed an awards program to recognize projects that exhibit exemplary use of integrated and interoperable building information modeling ${ }^{14}$. Additionally, the National Institute of Building Sciences, an organization authorized in 1974 to serve as an interface between government and the private sector to improve the building regulatory environment and facilitate the introduction of new and existing products and technology into the building process ${ }^{15}$, has also introduced a BIM initiative. It has established a committee referred to as NBIMS (the National Building Information Model Standard) as means of developing national standards for BIM ${ }^{16}$.

However, these developments are being driven in part by an initiative being sponsored by U.S. General Services Administration. The General Services Administration, which is the largest single procurer of design services in the United States, launched the GSA BIM initiative in 2003 with three specified intended outcomes; to maintain and advance design excellence, to bring in projects on-time and within budget, and to enable project life-cycle knowledge transfer. As of late 2006, the GSA's Office of the Chief Architect had completed 10 pilot projects and had 25 additional projects under way ${ }^{17}$. The GSA BIM initiative requires that all projects commissioned by the GSA utilize fully integrated Building Information Modeling for project delivery from design through construction beginning in Fiscal Year $2007{ }^{18}$. According to the GSA "the purpose of BIM is to make the design information explicit so that the design intent and program can be immediately understood and evaluated. They further stated that "a BIM-based approach supports 'on demand' generation of documents (e.g., drawings, lists, tables, and 3D renderings) from a consistent Building Information Model" ${ }^{19}$. The GSA's interest in greater coordination in the AEC (Architecture, Engineering, and Construction) industry was supported by research. A 2004 National Institute of Standards and Technology study found incompatible information costs the capital facilities industry at least $\$ 15.8$ billion a year. More importantly, these costs were attributed to all aspects of project design and delivery, including architecture, engineering, construction, and building owners ${ }^{5}$.

A central feature of the GSA mandate is interoperability. While the GSA CAD standards utilize the .DWG format as a file specification requirement ${ }^{20}$, BIM applications used on GSA projects must be based on the International Alliance for Interoperability's IFCs (Industry Foundation Classes) for preliminary design information. The IAI IFC is a construction information standard recognized by the International Standards Organization (ISO). Developed in part as a strategy for BIM applications to avoid the compatibility problems, this standard provides a specification for data structure to support an electronic project model that will be useful in sharing data across 
applications. Industry Foundation Classes enable the development of a common language for construction and are "intended to specify how 'things' that could occur in a constructed facility (including real things such as doors, walls, and fans as well as abstract concepts such as space, organization, information exchange, and process) should be represented electronically" 21 . Additionally, the IFC compliant file exchange format enables data to be exported from the BIM environments for input into other applications such as energy analysis tools ${ }^{21}$. This interoperability requirement has limited the applications that can be used on a GSA project as not all CAD applications are based on the International Alliance for Interoperability's IFCs. Compliant applications are Graphisoft ArchiCAD, Autodesk Architecture (formerly Architectural Desktop), Autodesk Revit, Bently Architecture, Gehry Technologies (CATIA), and Vectorworks Architect. ${ }^{22}$

The GSA is also promoting a 3D-4D BIM initiative using 4D models to support the understanding project phasing. According to the GSA "4D models, which combine a 3D model with time, allow Architects, Engineers, contractors, and GSA employees to communicate the proposed project phasing to all stakeholders" ${ }^{23}$ (Figure 1.). Specific issues being explored in the 3D-4D initiative are spatial program validation, 4D phasing, laser scanning, energy and sustainability, and design validation. This life-cycle approach is reflected in the GSA's comprehensive definition of BIM:

Building Information Modeling is the development and use of a multi-faceted computer software data model to not only document a building design, but to simulate the construction and operation of a new capital facility or a recapitalized (modernized) facility. The resulting Building Information Model is a data-rich, object-based, intelligent and parametric digital representation of the facility, from which views appropriate to various users' needs can be extracted and analyzed to generate feedback and improvement of the facility design ${ }^{24}$.

It can be assumed that as the demand for 4D operations (integrated scheduling) and 5D operations (integrated estimation) will further increase the demand for BIM expertise. More importantly, the emphasis on collaboration will drive changes for all associated with project delivery, particularly since the BIM-based project delivery will replace the traditional separations and fragmentations in the AEC industry ${ }^{25}$.

\section{Implications for AEC Education}

These initiatives and mandates suggest that competency with BIM applications will become increasingly important for engineers and construction management professionals as well as architects and, consequently, architectural and engineering education will be viewed as a resource for skill development with this technology. Therefore, educators in all fields related to the AEC industry must consider the role of BIM technology in both design and technical education.

Most major vendors have developed curricula to assist faculty and teachers to use their applications in courses. For example, Autodesk has developed curriculum for both Revit and Architectural Desktop (now Autodesk Architecture) and has support for educators on-line. 
Bentley and Vectorworks also have curriculum initiatives. ArchiCAD (Graphisoft) has a curriculum initiative for learning the software and their cost-estimating module. ArchiCAD was the first vendor to offer an integrated estimating module for BIM. The curriculum initiatives appear to be substantial For example, the ArchiCAD curriculum includes both seminar modules and studio projects ${ }^{26}$. The Revit curriculum includes lecture notes, student workbooks and datasets for delivering content on BIM, Revit-specific operations, and on design visualization ${ }^{27}$.

The extent to which these curricula are being utilized in education is not clear. However, BIM applications are being utilized in architecture and engineering curriculums to varying levels. A recent study of technology use in architectural engineering curriculums found that $64.7 \%$ of the respondents indicated they were either "very" aware or "moderately" aware and/or familiar with the concepts of building information modeling. However, only $28.8 \%$ of respondents identified one or more of the six GSA approved BIM applications as an application utilized in their curriculum, with Autodesk Architectural Desktop and Autodesk Revit being identified as the most commonly used. The most commonly used BIM-specific features were integration of extended data (i.e.: notes, schedules, specifications, etc). The generation of 2D documentation from model geometry and project management/coordination were also identified as commonly utilized features ${ }^{28}$.

A more cursory review of course offerings in architecture, architectural engineering, and construction programs has found Building Information Modeling related content in most curriculums ranging from classes dedicated to providing instruction on operations with specific BIM applications to classes using BIM as a general instructional platform in meeting other instructional goals. Many institutions have adopted BIM applications for use in design studios. Renee Cheng, Head of the Department of Architecture at the University of Minnesota, stated that "with the increased attention on BIM software and its increased availability to students, we are likely to see BIM permeate (if not dominate) the studios within the next few years" 29.

However, there is no accepted instructional strategy for teaching BIM in the AEC-related curricula $^{29}$. While supportive of BIM and technology in architectural education, Scheer ${ }^{30}$ argued that while "the students themselves are by and large eager to learn this 'next new thing', BIM presents very interesting and difficult questions about what to teach, what we want our graduates to know and the nature of architecture itself." He proposed that the faculty's limited experience with BIM poses a challenge because "like most practicing architects, the faculty is only starting to learn about BIM" and that "there are good reasons for keeping the curriculum largely intact, to continue producing graduates who see architecture as a cultural activity" 30 . Cheng suggested that BIM should be approached more cautiously. She stated that "BIM-centric construction/practice agenda threatens to expropriate time needed to train design thinking", adding that students should know what drives their tools" ${ }^{29}$. She cautioned that architectural education may be limited in what skills it can address:

The level of expertise required to intelligently design with BIM is significant, and serious consideration must be given to how it can be taught. Looking back, even the most admired architectural curricula never attempted to cover all the skills and knowledge that a mature architect should eventually have. Today, this is even more true given the level 
of complexity and specialization in the profession - and of course, the new demands of Integrated Practice.

The complexity of BIM in real-world applications illustrates Cheng's point that attempts to produce graduates with high levels of competencies with all processes associated with BIM could prove to be problematic. Specifically, the range of software applications associated with a fully-functional BIM is diverse. According to $\mathrm{Kymmell}^{31}$, the requisite software tools are organized as follows:

1. The applications which create BIM models (Autodesk's Revit, Graphisoft's ArchiCAD and Constructor, Bentley's Building, etc.),

2. The applications which view and analyze the BIM (Navisworks, Solibri, Commonpoint, etc.).

3. The software applications which process information which may be linked to the BIM (Microsoft applications - Word, Excel, Project, etc., other scheduling or database applications, etc.)

It is evident that allocating instructional time to enable students to develop competencies with such a broad range of applications would likely compromise other educational objectives. Therefore, strategies for effective curricular integration of BIM may require a more holistic approach. For example, For example, David Scheer ${ }^{30}$, of the Center for Integrated Design and Construction at the University of Utah College of Architecture + Planning proposed an approach that utilized BIM across the curriculum in design studios, technical classes, and in cultural subjects such as architectural history. The Civil and Environmental Engineering Department at Worcester Polytechnic Institute has integrated BIM into student research projects and graduate thesis, and have also integrated it in multiple undergraduate courses. Benefits to students identified by faculty included the development of and integrated view of a building and its components, better understanding of the construction process, advanced skill acquisition, and stronger collaboration with industry. Faculty stated that the introduction of BIM in their curricula promotes the achievement of their departmental measured outcomes and objectives related to practice, design, and independent learning ${ }^{25}$.

\section{Strategies for Implementing BIM}

It is evident from these industry developments that these mandates and initiatives will place considerable pressure on educators to integrate content related to BIM in their curriculums in order to produce graduates that have skills with this technology. However, decisions on the role of BIM in coursework must be made in the context of the larger curriculum and learning outcomes in order to provide students with the broad education needed for in the AEC industries. As a result, this paper proposes three strategies that have been utilized in coursework offered at an institution in which architecture and construction management are housed in the same college and share several core classes.

\section{Strategy 1: BIM skill development in design foundation coursework}

This approach to integrating BIM skill development takes as its point of departure the premise 
that 3D modeling applications may be more appropriately utilized as a design tool that considers CAD software not as a holistic design environment and representation tool but rather as an interface that can be "decomposed" to exploit specific features that are clearly aligned with outcomes. This reductionist strategy for introducing object-based computer modeling in studio is based on a proscriptive rather than inclusive approach to the use of the software. Assignments are structured to systematically limit the use of software features with the utilization of features tied directly to specific learning outcomes of the studio project. The advantages of this approach include maintained emphasis on traditional studio concepts and time allocation efficiencies.

\section{Selection of Software features and operational parameters}

The initial tasks required students to build physical models and manually produce plan and section drawings. The physical model was to use components dimensionally equivalent to those pre-defined in the digital context. After initial critiques, students refined their proposals using computer models. The starting point for the computer model was the proposal presented in the initial critique. This provided a physical object used as a reference in developing the computer model.

Students participating in this class had limited CAD experience which required course time to be allocated to specific aspects of basic CAD operations. The use of a BIM application enabled the students to learn these basics by drawing with walls rather than lines and other abstract 2D geometry. Additionally, the use of object properties to position and adjust objects in threedimensional space reduced the number of CAD commands and techniques needed to be covered. Basic commands identified as essential for the tasks included zooming and panning, use of the preset 3D views, object snaps, and 2D and 3D coordinate entry. The use of modification commands was limited to erase, move, offset, and copy.

Wall objects and slab objects were selected as the primary geometric components. The use of doors and windows was proscribed; openings within walls were to be created with a generic parametric opening available in the standard design palate. To accommodate vertical movement, the students were required to incorporate one stair element, but the geometry was limited to the generic style. Additional features such as railings were not permitted. A "start-up" file would be provided to students in the studio. The file included pre-modeled geometry which would provide the "project context"; an "un-editable" three dimensional column grid and a ground plane for the first project and a building mass and project area ground plane for the second. The default design palate was customized to eliminate some of the object-types the students would not be incorporating in their designs. The file was also pre-configured with two view-ports, a plan view and a 3D isometric view, with instructions that the viewport configuration must be retained over the duration of the project.

The wall and slab dimensions were identified as program requirements, and therefore were to be reflected in all physical modeling and manual orthographic representations. Walls and slabs were not to be angled or sloped vertically. In the computer model, students were not permitted to use materials or add lights. Only one camera was allowed in each project. The students were only permitted to change direction of the camera but were prohibited from modifying other parameters in order to reduce the operational knowledge associated with setting up their 
perspectives. Students were only required to use the software for the task-specific course activities. Project requirements included physical models as well as 2D orthographic documentation. While final project requirements were also media independent, students were required to include $3 \mathrm{D}$ representations of their models, including one that used a perspective view that communicated a sense of the interior space that was created.

\section{Results and Observations}

Since the initial offering, this project has been used in both introductory studios and in beginning and intermediate CAD courses. While this strategy does not attempt students to many of the advanced analysis, documentation, and representational features that the Building Information Modeling applications, it does provide a mechanism for students to develop an understanding of the conceptual underpinnings of object-based modeling, thus providing a foundation for the use of more advanced applications of BIM later in the design curriculum as well as in the profession.

\section{Strategy 2: BIM skill development in design foundation coursework}

An undergraduate course offered to Construction Management students was introduced into the curriculum in the fall semester 2007 in a bid to keep up with emerging industry trends and to equip students with practical problem solving skills that will make them not only competitive but effective project leaders in their future careers. The class utilized the BIM curriculum provided by Graphisoft and is composed of both theory and studio components. Industry experts were also invited to share their experiences on BIM with the students and provide insight into industry trends.

The class was taught using Vico construction solutions software including: GS Constructor 2007, GS Estimator 2007, and GS Control 2007. The Constructor 2007 is used to teach the students basic modeling skills based on the parametric object technology. Students were also encouraged to investigate other 3D knowledge rich parametric modeling systems such as Bentley Architecture and Structure, Revit Architecture, structure and MEP, Digital Project (Catia-based), Navisworks, and Structure works. Particular emphasis was placed on ensuring that the students develop an understanding of the BIM process as opposed to mastering specific software. The course started with basic software tutorial and built up gradually to more complex modeling techniques. Students were required to attend all lectures and labs and work on all class exercises including reading assignments on specific topics related to the BIM process. Students enrolled in the fall 2007 class were required to complete a term project in which they were provided with a set of drawings from which they developed a comprehensive BIM model, including architectural, structural, and MEP systems. They were then required to extract quantities from the model into G.S Estimator in which they prepared detailed costing for the project. They were also required to develop a 4D schedule using G.S Control 2007 and optimize their proposed schedules using the line of balance scheduling.

\section{Results and Observations}

Intelligent object technology as described by Lee et al, ${ }^{35}$ mimics the logical design intent of these objects thus making it easier for students to understand the relationship between different 
building systems. However, based on initial interviews with the students enrolled in the class, junior students tended to be excited with the modeling process while senior students tended to feel that the modeling function should be the role of designers and that the class should focus more on aspects of elaborating means and methods (i.e. how the project will actually be "put together" and the sequence of construction activities). The senior students however tended to have a better grasp of BIM overall concepts. It is the author's opinion that BIM should be taught in stages, possibly two or three levels with the basic modeling being introduced at an earlier stage while more analytical components are introduced at a later stage (introductory level, medium level and advanced level).

\section{Strategy 3: Academic and Industry Interaction}

The third approach involved using graduate research as a mechanism for interaction directly with construction professionals. An example is on-going dissertation research being conducted with Rudolph Libbe Companies (RLCOS), a leading general contractor in North West Ohio. This research is investigating the value of BIM solutions in streamlining construction processes. Specifically, this research is focused on identifying the level of detail that needs to be included within a working Building Information Model in order to obtain valuable information for construction orchestration. Many companies trying to implement BIM are trying to understand the cost and benefit relationship of the BIM process. A significant objective of this study is to develop a framework that will assist industry professionals in optimizing the level of detail recommended for a BIM model based on the intended use.

\section{Preliminary Results and Observations}

Initial results of this study indicate that project managers working on construction sites can benefit from information derived from the BIM models including: specific section views of problem areas, automated clash detection between building systems, simulation of construction sequencing, generation of schedules and quantities for material ordering. Preliminary results suggest that BIM's typically will evolve from a design-intent data source to an installation-intent data source. Preliminary results also suggest that Building Information Models must be considered in terms of output requirements. For example, a BIM intended that will be used as a visualization tool will require a different detail-optimization than a BIM used for postconstruction facility management.

Project managers are often faced with problems that require quick decision making to avoid delays and other inconsistencies. The outcome of this study would provide a useful basis for training students on the importance of understanding the different types of BIM models being used in industry. An understanding of the level of detail required at different stages is also useful in illustrating the overall virtual design and construction process and the evolution of the model in a virtual environment as project participants add value to the project. By understanding that a BIM model does not need to be complex in order to be valuable would be helpful in demystifying the idea that BIM is complicated and therefore difficult to use in coursework. Instead, students will have a deeper understanding of the BIM process and the use of the model for enhancing collaboration between project participants. 


\section{Conclusions and summary}

The increasing adoption of BIM in the AEC industry is a result not only from the inherent benefits such as improved productivity but also in response to the initiatives of both the design and construction industry such as AGC, TAP, NIBS, and GSA. Specifically, the GSA's motivation in promoting BIM is based on the premise that BIM allows design intent and program requirements to be easily understood while also enabling on demand generation of documents (drawings, lists, tables) from a consistent. Therefore, there is a clear need for AEC curricula to keep in sync with emerging Industry trends. It has been shown that OOP-based CAD systems have the potential to alter the design and construction process through the concept of modelcentric design and use of integrated databases that allow more collaboration between project participants. It is important to emphasis that the potential benefits of BIM are not just in the digital model but the embedded information.

This paper has described three approaches that are being used in architecture and construction management courses. The first is the reductionist strategy based on prescriptive rather than inclusive approach to use of software. In this approach assignments are structured to systematically limit the use of software feature with the utilization of features tied directly to specific learning outcomes. The second approach incorporates elements of the first approach but also involves the use of the software in a linear pattern that parallels the sequence of design and construction activities that is typically utilized in the AEC industry. Students develop conceptual models for extracting conceptual estimates and 4D sequencing and progressively advance to more comprehensive models that enable extraction of detailed estimates and comprehensive schedules for construction sequencing. The third approach involves the use of graduate students working with industry professionals and working on real projects. This approach has the potential for uncovering unique practical approaches for the use of this new technology. The students are also able to better appreciate the BIM process and its challenges associated with its adaptation in a real world environment.

However, given the need for students to develop skills to work collaboratively with other disciplines, all three strategies would benefit by revisions that would facilitate a more interdisciplinary approach. Where possible, courses that are taken jointly by students in related disciplines such as architecture and construction management should utilize technology associated with BIM in order to emphasize the collaborative nature of the BIM process. Common coursework in areas such as structures and building systems provide examples of classes that could be redesigned to be offered as interdisciplinary courses. Additionally, even classes that are not common to different disciplines can be utilized for integration of BIM content and collaborative learning. In particular, curricular coordination between architecture and construction management courses to structure common or parallel assignments would develop technical skills for students in both programs while fostering a collaborative learning environment which would ultimately enhance interpersonal communication skills and provide students with a more well-rounded perspective on the project delivery process. Linking an exercise in an architecture HVAC class to an exercise in a construction cost estimating course is an example of this strategy that should be explored. 
In conclusion, educators must make it a priority to continue investigating the most appropriate strategies for incorporating emerging technologies such as BIM in order to enhance professional preparation while maintaining the intended outcome of their respective educational programs. Therefore, based on experiences with the three strategies described in this paper as well as those documented at other institutions, a more holistic approach to BIM integration accompanied by an emphasis on collaboration and interdisciplinary instruction should be used as the basis for curricular revision and development. Additionally, the rapid advances in technology illustrates that faculty must be committed to ongoing development of their own skills with digital technologies. Given the rapid adoption of such technologies and the extent to which the AEC industry is being dramatically transformed by their implementation, faculty who do not their own skill development a priority will likely become ineffective and irrelevant in AEC education.

\section{Bibliography}

1 Roberts H. (2004). AEC bytes: The Importance of Parametrics in Building Information Modeling. www.aecbytes.com/viewpoint/2004/issue_5.html

2 Smith, D. (2007). An Introduction to Building Information Modeling (BIM) Journal of Building Information Modeling. Fall 2007. http://www.facilityinformationcouncil.org/bim/pdfs/jbim_fall07.pdf

3 Murray, Lynn. (2008) Building Information Modeling Takes Architectural Design to a New Dimension. Design Cost Data. http://www.dcd.com/insights/insights_sepoct_2007.html

4 Elvin, G. (2006). Integrated Practice in Architecture: Mastering Design-Build, Fast-Track, and Building Information Modeling. Wiley and Sons. (2007).

5 Gallaher, M., O'Connor, A., Dettbar, J., and Gilday, L. (2006). Cost analysis of inadequate interoperability in the US capital facilities industry. http://www.bfrl.nist.gov/oae/publications/gcrs/04867.pdf

6 Johnson, S. (1998). What's in a representation, why do we care, and what does it mean? Examining the Evidence from Psychology. In Automation in Construction. 8 (1): 15-24.

7 Birx, G. BIM Evokes Revolutionary Changes to Architecture Practice at Ayers/Saint/Gross. In AIA Architect. (2005). http://www.aia.org/aiarchitect/thisweek05/tw1209/tw1209changeisnow.cfm

8 Khamlani, L. (2004). The IFC Building Model: A Look Under the Hood. AECbytes Feature (March 30, 2004). http://www.aecbytes.com/feature/2004/IFCmodel.html

9 Hagan, S, Graves, T, Matta, C., and Kam, C. (2005). Building Information Models- Towards a common industry framework. http://www.nibs.org/FIC/BIM82905/4_GSA_BIM.pdf

10 Kilkelly, M. (2000). Off the Page: Object Oriented Construction Drawings. In The ACADIA Conference Proceedings: Eternity, Infinity, and Virtuality. Washington DC: 147 - 151.

11 Ethier, S. \& Ethier, C. (2000). Instant AutoCAD architectural desktop. New York: Prentice Hall.

12 Mondero, J. (2000). Parametric Design: A Review and Some Experiences. In Automation in Construction. 9 (4): 369-377.

12 Kemlani, L. (2006). The AGC's BIM Initiatives and the Contractor's Guide to BIM. In AECbytes. October 11, 2006. http://www.aecbytes.com/buildingthefuture/2006/AGC_BIM.html

13 Mashburn, H. (2006). Building Information Modeling: A Catalyst for Change: AGC brings contractors' perspectives to emerging design and construction technology. Constructor Magazine - Inside AGC. (May/June 2006). http://constructoragc.construction.com/insideAGC/archives/2006-05presMsg.asp

14 AIA Technology in Architectural Practice Call for Entries (2008). http://www.aia.org/SiteObjects/files/TAP_BIM_2008_cfe_final_010808.pdf

15 National Institute of Building Sciences. (2008). http://www.nibs.org/aboutnibs.html

16 National Building Information Model Standard project (NBIMS): http://www.facilityinformationcouncil.org/bim/

17 The GSA's BIM Pilot Program. (2005). http://www.aia.org/SiteObjects/files/gsa.pdf

18 GSA Mandates on Building Information Modeling. AIA PodNet. 2008. http://www.aia.org/pod_kamhagan 
19 Matta, C., Kam, C., Clevenger, C., and Ho, P. (2006). GSA's National 3D-4D BIM Program. http://www7.nationalacademies.org/ffc/2calvin_kam_gsa.pdf

20 GSA CAD Standards: http://www.gsa.gov/gsa/cm_attachments/GSA_DOCUMENT/CAD_standards_R2NY1k_0Z5RDZ-i34K-pR.pdf

21 Khemlani, L. (2004). The IFC Building Model: A Look Under the Hood. AECbytes Feature (March 30, 2004). http://www.aecbytes.com/feature/2004/IFCmodel.html

22 GSA Presentation on 3D-4D Building Information Modeling Initiative. (2006). Presented at Getting Real: Design Ethos Now. $94^{\text {th }}$ ACSA annual meeting. Salt Lake City, UT

23 US General Services Administration. 3D-4D Building Information Modeling. (2006). 4-D Phasing. http://www.gsa.gov/Portal/gsa/ep/contentView.do?programId=12122\&channelId=$18161 \&$ ooid=20917\& contentId=21705\&pageTypeId=8195\&contentType=GSA_BASIC \&programPage=\%2Fe p\%2Fprogram\%2FgsaBasic.jsp\&P=PMBIM

24 GSA BIM Guide Series 01 Veriosn 0.60. (2007). http://www.gsa.gov/gsa/cm_attachments/GSA_DOCUMENT/GSA_BIM_Guide_v0_60_Series01_Overview_05-14-07_R2C-a3-1_0Z5RDZ-i34K-pR.pdf

25 Salazar, G., Mokbel, H., and Aboulezz, M. (2006). The Building Information Model in the Civil and Environmental Engineering Education at WPI. Published in the Proceedings of the ASEE New England Section 2006 Annual Conference. (2006).

26 Graphisoft ArchiCAD: BIM curriculum: http://www.graphisoft.com/community/education/curriculum/

27 Autodesk Revit Architecture: University and College Classroom Curriculum: BIM and Visualization Curriculum. http://usa.autodesk.com/adsk/servlet/index?siteID=123112\&id=8029689\&linkID=9243097

28 Guidera, S. (2007). Digital Design, BIM, and Digital Fabrication: Utilization and Integration in Architectural Engineering Curriculums. Published in the Proceedings from 2007 Annual Conference of the American Society for Engineering Education. June 22-25, (2007) . Honolulu , Hi

29 Cheng, R. Questioning the Role of BIM in Architectural Education. AECbytes Viewpoint \#26 (July 6, 2006): http://www.aecbytes.com/viewpoint/2006/issue_26.html

30 Scheer, D. (2006). From an Educational Perspective: BIM in the Architectural Curriculum. $\mathrm{http}: / / \mathrm{www} 7$. nationalacademies.org/ffc/david_scheer_utah.pdf

31 Kymmel, W. (2006). Outline for a BIM Curriculum. http://www7.nationalacademies.org/ffc/willem_kymmell_csu.pdf

Figure 1. GSA 3D-4D

\begin{tabular}{|c|c|c|c|}
\hline \multicolumn{4}{|c|}{ Technology $\longrightarrow$ Project Area $\longrightarrow$ Improvements } \\
\hline $\begin{array}{l}\text { 3D Laser } \\
\text { Scanning }\end{array}$ & - As-built Information & - As-Constructed Information & \multirow{6}{*}{$\begin{array}{ll}\text { - } & \text { Quality } \\
\text { - } & \text { Accuracy } \\
\text { - } & \text { Coordination } \\
\text { - Efficiency }\end{array}$} \\
\hline $\begin{array}{l}\text { 3D Geometric } \\
\text { Models }\end{array}$ & $\begin{array}{ll}\cdot & \text { Site } \\
\text { - } & \text { Architectural } \\
\text {. } & \text { Structural } \\
\end{array}$ & $\begin{array}{ll}\cdot & \text { MEP } \\
\cdot & \text { Fabrication/Construction } \\
& \text { Tolerance }\end{array}$ & \\
\hline $\begin{array}{l}\text { Design and } \\
\text { Construction } \\
\text { Coordination }\end{array}$ & $\begin{array}{l}\text { Coordination between } \\
\text { disciplines }\end{array}$ & - Clash Detection & \\
\hline 4D Models & $\begin{array}{ll}\cdot & \text { Project Phasing } \\
\text { - } & \text { Tenant Phasing }\end{array}$ & $\begin{array}{ll} & \text { Construction Sequencing } \\
\text { - } & \text { Traffic Studies }\end{array}$ & \\
\hline BIM Models & $\begin{array}{l}\text { Site } \\
\text { - Architectural } \\
- \text { Space } \\
- \text { Zone/Circulation }\end{array}$ & $\begin{array}{ll}\cdot & \text { Structural } \\
\text { - } & \text { Mechanical } \\
\text { - } & \text { Equipment Information } \\
\text { - } & \text { Maintenance Schedules } \\
\end{array}$ & \\
\hline $\begin{array}{l}\text { BIM-analysis } \\
\text { Applications }\end{array}$ & $\begin{array}{ll}\text { - } & \text { Program/Asset Management } \\
\text { - } & \text { GIS } \\
\text {. } & \text { Energy Analysis } \\
\text {. } & \text { CFD Analysis }\end{array}$ & $\begin{array}{ll}\cdot & \text { Acoustic } \\
\text { - } & \text { Cost Estimating } \\
\text { - } & \text { Equipment Inventory } \\
\text { - } & \text { Facility Management }\end{array}$ & \\
\hline
\end{tabular}

